\title{
ОПТИМІЗАЦІЯ ОСНОВНИХ ПАРАМЕТРІВ М'ЯКОГО ІНТРАПЕРИКАРДІАЛЬНОГО ПРИСТРОЮ ДЛЯ ПІДТРИМКИ НАСОСНОЇ ФУНКЦІї СЕРЦЯ
}

\author{
Фабрицій Ю. Й., Максименко В. Б., д.м.н., проф., Тарасова Л. Д., к.т.н., доц. \\ fabr09@ukr.net,maksymenko.vitaliy@gmail.com, larisa.tarasova.dmitrievna@gmail.com \\ Факультет біомедичної інженерії \\ Національний технічний університет України \\ «Київський політехнічний інститут ім. Ігоря Сікорського» \\ Київ, Україна
}

\begin{abstract}
Реферат - Трансплантація серия залитається остаточною терапією для пацієнтів з розвиненою серцевою недостатністю. Однак, внаслідок обмеженої доступності донорських органів та тривалості очікування, інтраперикардіальні пристрої для підтримки насосної функиї серия є перспективною альтернативою. В роботі розглянуто форму шлуночків у вигляді конічних оболонок, щзо в більшій мірі відповідає дійсності. Це дозволило визначити максимальні напруження, щуо виникають у стінках шлуночків, які залежать від їх анатомічної форми та рівня заповнення кров'ю, $i$, таким чином, виявити зону прикладення зовнішнього тиску при прямому масажі серия. Одержані результати дозволили розробити більи точну комп'ютерну модель нижніх відділів серия $і$ запропонувати нове технічне рімення інтраперикардіального пристрою для підтримки насосної функиії серия.

Ключові слова - інтраперикардіальні пристрої, серцева недостатність, сепсис, комп'ютерне моделювання.
\end{abstract}

\section{I. Ветуп}

Відомими засобами допомоги, що подовжують життя при серцевій недостатності, $\epsilon$ лікарська терапія (використовується у $10 \%$ випадків) та тимчасова механічна підтримка серця, що передбачає використання або внутрішньо аортального балонного насосу (до 20 \% випадків), або через шкірної внутрішньосудинної насосної систем (50-60 \% випадків). Іншим напрямком допомоги $\epsilon$ довготривалі системи підтримки серця або його повна заміна. Основним показанням до застосування тимчасової механічної системи підтримки $є$ загрозлива для життя відмова серцевосудинної системи з гострою втратою насосної функції серця, клінічними проявами якої є: Хвилинний об'єм кровообігу (ХОК) $<50$ \% (норма - 4...5 літрів за хвилину); фракція вигнання $(Ф В)<30 \%$ (норма $-50 \ldots 60 \%$ ); серцевий індекс $(\mathrm{CI})<<1,8$ л/хв $/ \mathrm{m}^{2}$ (норма $-2,5 \ldots 4$ літри за хвилину на кв. м поверхні тіла).

Ефективність застосування тимчасової механічної підтримки серця призводить до збільшення інвазивності для пацієнта. 3 одного боку, основними причинами, що призводять до втрати функції серця $є$ сепсис та гострий ін- фаркт міокарда, а існуючи системи тимчасової механічної підтримки серця непридатні для лікування пацієнтів з сепсисом [1-4]. 3 другого боку, недостатня терапія втраченої насосної функції, що трапилася протягом декількох хвилин, призводить до незворотних розладів життєвих функцій, і як результат, до загальної відмови органів, і навіть, до смерті пацієнта [5-7]. 3 огляду на це, розробка мінімально інвазивних систем для тимчасової підтримки насосної функції серця без контакту з кров'ю є перспективним напрямком біомедичної інженерії.

\section{II. Принципова конструкція механічного пристрою}

для підтримки насосної функції серця

Існує декілька модифікацій пристроїв, які використовуються інтраперикардіально 3 метою підтримки насосної функції серця [8-11]. В цих пристроях комплексний рух у серці досягається завдяки функціональному розташуванню численних стискаючих елементів, що просторово орієнтовані у м'якій матриці-манжеті конусоподібної форми. М'язові шари серця, що розташовані у спіральних та кругових структурах, одночасно здійснюють скручуючі 
та стискуючі рухи. На рис.1 наведено елементперикардіального пристрою, який було взято за основу при розрахунках у цій роботі.

Пристрій являє собою імплантат із синтетичного матеріалу, що розташовують мінімально інвазивно навколо серця. Оскільки різноманітні конструкції імплантатів та застосовувані для них матеріали широко описані в літературі [12-13], не будемо на них зосереджувати увагу.
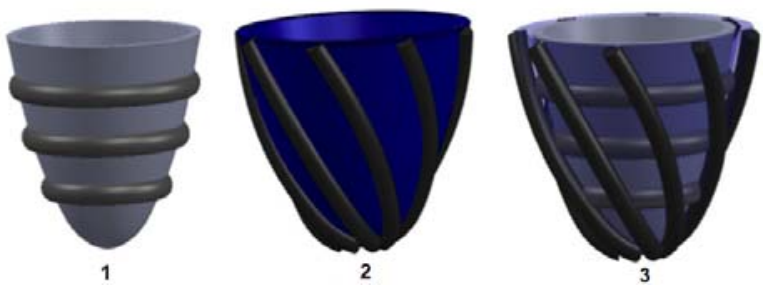

Puc. 1. Варіанти конструктивного виконання основного елементу перикардіального пристрою

Принцип роботи такого механічного пристрою полягає в наступному: система підтримує синхронізований із серцевою діяльністю пацієнта (рис.2) прямий масаж серця за допомогою компресії серцевого м'яза i, тим самим, викид крові зі шлуночків. Фаза наповнення манжети синхронізується по найбільшому зубцю $R$ і триває період $T R$. Період $T s$ манжета знаходиться у надутому стані. Після закінчення цього періоду відбувається здуття манжети, яке триває період $T d$.

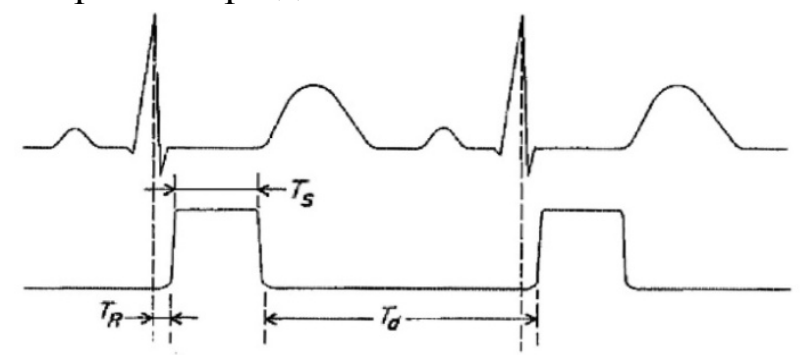

Puc. 2. Синхронізація фаз наповнення та здуття манжети 3 електрокардіограмою серця

Основними перевагами конструкції механічного пристрою $\epsilon$ :

- Мінімально інвазивне застосування пристрою без прямого контакту з кров'ю;

- Механічна підтримка правого і лівого шлуночків;

- Можливість прямого застосування медикаментів;

- Ресинхронізація серця.

Таким чином, розробка нової конструкції механічного пристрою або удосконалення існуючого $\epsilon$ актуальною проблемою.
Метою даної роботи було зробити більш точну комп'ютерну модель нижніх відділів серця. Саме наявність такої моделі і дозволить запропонувати нове технічне рішення інтраперикардіального пристрою для підтримки насосної функції серця.

\section{III. Визначення зони прикладання зовнішнього тиску при прямому масажі серця}

В даній роботі всі розрахунки базувалися на тому, що форма шлуночків серця має вигляд конічних оболонок, що в більшій мірі відповідає дійсності (рис. 3).

Розглянемо порожнину одного із шлуночків, наприклад, лівого (ЛШ), який заповнений на висоту Н. Для цього введемо наступні позначення: $\delta$ - товщина стінки шлуночка; $\alpha$ - кут при вершині конусу.

Для оптимального розподілу сили, яка прикладається до міокарда, необхідно визначити перерізи 3 максимальними окружними $\left(\sigma_{0}\right)$ i меридіональними $\left(\sigma_{M}\right)$ напруженнями шлуночка під час систоли. Для цього проведемо довільний переріз $m-n$ на висоті «y». Тиск рідини в перерізі $m-n$ дорівнює:

$$
p=\gamma(H-y)
$$

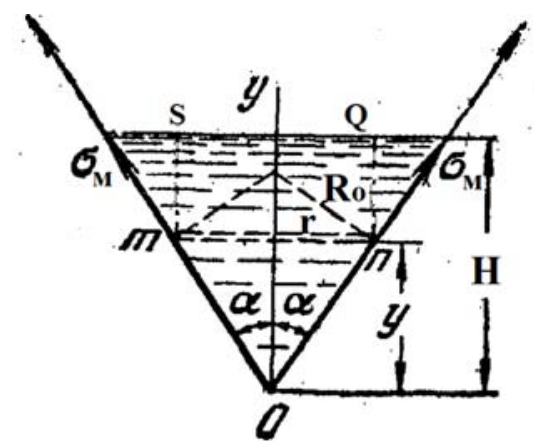

Puc. 3. Схема форми шлуночків серця у вигляді конічних оболонок

Окружні напруження визначимо з рівняння Лапласа:

$$
\frac{p}{\delta}=\frac{\sigma_{0}}{R_{0}}+\frac{\sigma_{M}}{R_{M}}
$$

Оскільки $R_{M} \rightarrow \infty$, рівняння (2) набуває вигляду:

$$
\frac{p}{\delta}=\frac{\sigma_{0}}{R_{0}}
$$

Знайдемо залежність між окружним радіу- 
сом $R_{0}$ і висотою довільного перерізу «у», беручи до уваги, що

$$
\operatorname{tg} \alpha=\frac{r}{y}
$$

Звідси знаходимо значення радіусів $r$ i $R_{0}$ :

$$
\begin{aligned}
& r=y \operatorname{tg} \alpha=R_{0} \cos \alpha \\
& R_{0}=\frac{r}{\cos \alpha}=\frac{y \operatorname{tg} \alpha}{\cos \alpha}
\end{aligned}
$$

Залежність окружного напруження від висоти «у» набуває вигляду:

$$
\begin{gathered}
\sigma_{0}=\frac{p}{\delta} R_{0}=\frac{\gamma(H-y)}{\delta} \frac{y \operatorname{tg} \alpha}{\cos \alpha}= \\
=\frac{\gamma}{\delta} \frac{\operatorname{tg} \alpha}{\cos \alpha}(H-y) y
\end{gathered}
$$

Наступними розрахунками визначимо, на якому рівні діють максимальні окружні напруження. Для цього проведемо наступні операції:

$$
\sigma_{0}=K(H-y) y
$$

де $K=\frac{\gamma}{\delta} \frac{\operatorname{tg} \alpha}{\cos \alpha}$,

$$
\frac{d \sigma_{0}}{d y}=K(H-2 y)=0
$$

тобто $H-2 y=0$, звідси $y=\frac{H}{2}$. Отримане значення висоти $y=\frac{H}{2}$, підставимоу формулу (8):

$\sigma_{0}^{M A X}=K\left(H-\frac{H}{2}\right) \frac{H}{2}=K \frac{H^{2}}{4}=\gamma \frac{H^{2}}{4 \delta} \frac{\operatorname{tg} \alpha}{\cos \alpha}$

Отже, максимальне окружне напруження виникає в конічній оболонці на висоті $y=\frac{H}{2}$ від вершини конусу.

Меридіональне напруження $\sigma_{M}$ на рівні $m-n$ знайдемо з тієї умови, що вертикальні складові меридіональних зусиль у стінках конічної оболонки врівноважуються вагою об'єму $\mathrm{S}_{\mathrm{m}} \mathrm{O}_{\mathrm{n}} \mathrm{Q}$ рідини:

$$
\begin{gathered}
\left(\sigma_{M} \cos \alpha\right)(2 \pi r \delta)=\gamma \frac{1}{3} \pi r^{2} y+ \\
+\gamma(H-y) \pi r^{2} \gamma \pi r^{2}\left(-\frac{2}{3} y\right)
\end{gathered}
$$

Рівняння (10) представимо у вигляді:

$$
2 \sigma_{M} \delta \cos \alpha=\gamma r\left(H-\frac{2}{3} y\right)
$$

Наступними розрахунками визначимо максимальне меридіональне напруження. Для цього проведемо наступні операції:

$$
\begin{aligned}
& \sigma_{M}=\frac{\gamma r}{2 \delta \cos \alpha}\left(H-\frac{2}{3} y\right)=\frac{\gamma(y \operatorname{tg} \alpha)}{2 \delta \cos \alpha}\left(H-\frac{2}{3} y\right)= \\
& =\frac{\gamma \operatorname{tg} \alpha}{2 \delta \cos \alpha}\left(-\frac{2}{3} y\right) y \\
& \sigma_{M}=K_{M}\left(H-\frac{2}{3} y\right) y \text {, }
\end{aligned}
$$

$$
\frac{d \sigma_{M}}{d y}=K_{M}\left(H-\frac{4}{3} y\right)=0
$$

Тобто $H-\frac{4}{3} y=0$, звідси $y=\frac{3}{4} H$. Підставимо одержаний вираз у формулу (12):

$$
\begin{gathered}
\sigma_{M}^{M A X}=\frac{\gamma \tan \alpha}{2 \delta \cos \alpha}\left(H-\frac{2}{3} \cdot \frac{3}{4} H\right) \frac{3}{4} H= \\
=\frac{3}{16} \frac{H^{2}}{\delta} \frac{\gamma \tan \alpha}{\cos \alpha}
\end{gathered}
$$

Таким чином, максимальне меридіональне напруження в конічній оболонці виникає на висоті

$$
y=\frac{3}{4} H=0,75 H
$$

Визначимо залежність окружних і меридіональних напружень, що виникають у стінках шлуночка, від висоти заповнення за умови:

- $\quad$ середня товщина стінки ЛШ $\delta=7$ мм;

- $\quad$ кут при вершині конусу $\alpha=15^{\circ}$;

- $\quad$ висота у $=0,5 \mathrm{H}$.

3 графіка на рисунку 4 видно, що окружні та меридіональні напруження зростають зі збільшенням висоти заповнення. Значення меридіональних напружень зростає повільніше, ніж окружних: при заповненні шлуночка на $0,4 \cdot 10^{2}$ м значення напружень відповідно дорівнюють 5,41 та 7,99 Па, а вже при заповненні на $2,8 \cdot 10^{2}$ м становлять 262,69 та 391,6 . 


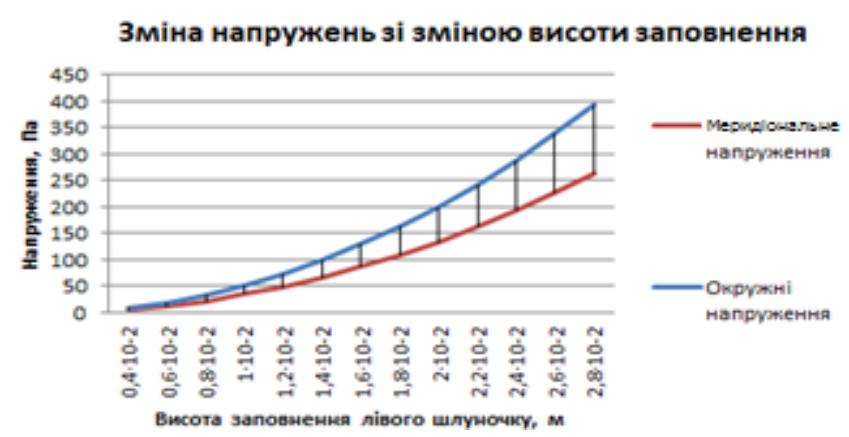

Рис. 4. Залежність напружень від висоти заповнення ЛШ

Визначимо залежність окружних і меридіональних напружень від геометрії шлуночка за умови:

- $\quad$ висота заповнення шлуночка $\mathrm{H}=2 \mathrm{~cm}$;

- $\quad$ висота $\mathrm{y}=0,5 \mathrm{H}$;

- середня товщина стінки ЛШ $\delta=7$ мм (при дослідженні зміни кута при вершині конусу);

- $\quad$ кут при вершині конусу $\alpha=15^{\circ}$ (при дослідженні зміни товщини стінки).

3 графіків на рисунках 5 та 6 видно, що окружні та меридіональні напруження спадають зі збільшенням товщини шлуночка, але зростають зі збільшенням кута при вершині конуса шлуночка.

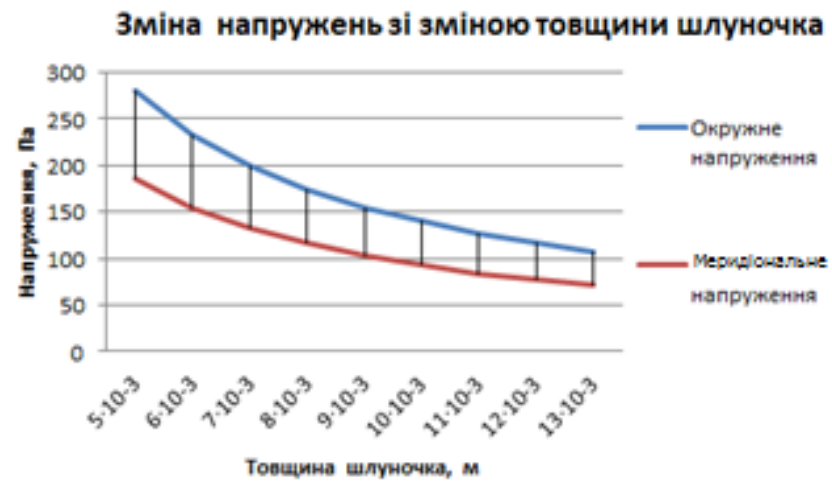

Puc. 5. Залежність напружень від товщини ЛШ

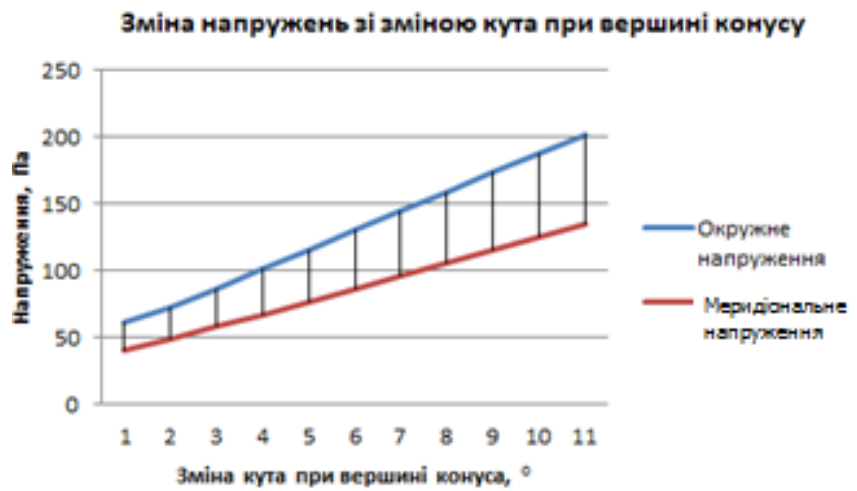

Рис. 6. Залежність напружень від кута при вершині конуса ЛШ

\section{IV. Висновки}

Максимальні напруження, що виникають у стінках шлуночків, залежать від анатомічної форми шлуночків, рівня заповнення кров'ю і зосереджені на відстані $0,5 \ldots 0,75$ від висоти заповнення шлуночків - фактично, це зона, куди треба прикладати зовнішній тиск при прямому масажі серця.

Отримані результати дозволили виявити залежність окружних і меридіональних напружень, що виникають у стінках шлуночка від висоти заповнення та геометрії шлуночка та розробити більш точну комп'ютерну модель нижніх відділів серця, і на підставі цього, запропонувати нове технічне рішення інтраперикардіального пристрою для підтримки насосної функції серця.

\section{ПЕРЕЛІК ПОСИЛАНЬ}

[1] Німецьке зареєстроване товариство з сепсису; Центр контролю та попередження захворюваннь, www.cdc.gov

[2] Федеральне міністерство освіти та досліджень: http:// //www.gesundheitsforschung-bmbf.de/de/774.php

[3] Б. Браун АГ: http://www.sepsis.bbraun.de/

[4] Бубличенко Л. И. Сепсис, инфекционные заболевания, в кн.: Многотомное руководство по акушерству и гинекологии/ Хаскин С. Г.-М., 1964.-Т. 3, кн. 2.

[5] Шлапоберский В. Я., Хирургический сепсис. (Клиника и лечение).- М, 1952.

[6] Sepsis in General Surgery: The 2005-2007 National Surgical Quality Improvement Program Perspective - Archives of Surgery, 2010 July. -Vol. 145 No. 7.

[7] AmericanHeartAssociation (AHA) - www.aha.org.

[8] Пат. US7060023B2 США, Перикардіальне пристосування i методи його застосування/Роналд Г. Френч. №09/963848; заявл. 25.09.01; опубл.

[9] Пат. 5131905 США, Зовнішне кардіологічне пристосування/Роналд К.Грутелс. - №552589; заявл. 16.07.90; опубл. 21.07.92.

[10] Пат. 3371662 США, Пристрій для автоматизованого ефективного масажу серця/Джозеф Хейд. - №521006; заявл. 17.01.66; опубл. 5.03.68.

[11] Пат. 5256132 США, Кардіологічне пристосування для зовнішнього застосування/Роберт В. Снідерс. - №930985; заявл. 17.08.92; опубл. 26.10.93.

[12] Пат. 3613672 США, Механічне шлуночкові пристосування у вигляді «чаші»/Пітер Шіф. - №840253; заявл. 9.06.69; опубл. 19.10.71.

[13] Пат. 5713954 США, Кардіологічне пристосування для шлуночків серця/Мейр Розенберг. - №490080; заявл. 13.06.95; опубл. 3.02.98. 


\title{
ОПТИМИЗАЦИЯ ОСНОВНЫХ ПАРАМЕТРОВ МЯГКОГО ИНТРАПЕРИКАРДИАЛЬНОГО УСТРОЙСТВА ДЛЯ ПОДДЕРЖАНИЯ НАСОСНОЙ ФУНКЦИИ СЕРДЦА
}

\author{
Фабриций Ю. Й., Максименко В. Б., д.м.н., проф., Тарасова Л. Д., к.т.н., доц. \\ fabr09@ukr.net \\ maksymenko.vitaliy@gmail.com \\ larisa.tarasova.dmitrievna@gmail.com \\ Факультет биомедицинской инженерии \\ Национальный технический университет Украины \\ «Киевский политехнический институт им. Игоря Сикорского» \\ Киев, Украина
}

\footnotetext{
Реферат - Трансплантация сердия остается окончательной терапией для пациентов с развитой сердечной недостаточностью. Однако, вследствие ограниченной доступности донорских органов и длительности ожидания, интраперикардиальные устройства для поддержки насосной функиии сердияа являются перспективной альтернативой. В работе рассмотрена форма желудочков в виде конических оболочек, что в большей степени соответствует действительности. Это позволило определить максимальные напряжения, возникающие в стенках желудочков, которые зависят от их анатомической формы и уровня заполнения кровью, и таким образом определить зону приложения внешнего давления при прямом массаже сердиа. Полученные результаты позволили разработать более точную компьютерную модель нижних отделов сердия и предложить новое техническое решение интраперикардиального устройства для поддержания насосной функиии сердия.

Ключевые слова - интраперикардиальные устройства, сердечная недостаточность, сепсис, компьютерное моделирование.
} 


\title{
OPTIMIZATION OF THE BASIC PARAMETERS OF A SOFT INTRAPERICARDIAL DEVICE TO SUPPORT THE PUMPING FUNCTION OF THE HEART
}

Y. Fabritsii, V. Maksymenko, Doctor of Medical Sciences, Professor, L.Tarasova, Candidate of Technical Sciences, Associate Professor

fabr09@ukr.net maksymenko.vitaliy@gmail.com larisa.tarasova.dmitrievna@gmail.com

Faculty of Biomedical Engineering National Technical University of Ukraine "Igor Sikorsky Kyiv Polytechnic Institute"

Kyiv, Ukraine

\begin{abstract}
Heart transplantation remains the definitive therapy for patients with advanced heart failure; however, owing to limited donor organ availability and long wait times, intrapericardial devices to support the pumping function of the heart are a promising alternative. The paper considers the form of ventricles in the form of conic membranes, which is more in line with reality. This allowed to determine the maximum stresses occurring in the walls of the ventricles, which depend on their anatomical form and level of filling with blood, thus, determine the zone of application of external pressure in the direct heart massage. Thus, the obtained results allowed to develop a more precise computer model of the lower parts of the heart, which in turn allows us to propose a new technical solution for intraperitoneal device to support the pumping function of the heart.

Keywords - intrapericardial devices, heart failure, sepsis, computer simulation.
\end{abstract}

